\title{
Mapping the Influence of Institutional Factors
}

The previous chapters covered blame games in the UK, Germany, and Switzerland that varied considerably on a number of dimensions. Some blame games involved heated interactions that put political incumbents under considerable pressure, others mainly focused on the actions or omissions of administrative actors. In some blame games, incumbents could draw on considerable support from the governing majority, during others, they stood alone against criticism and blame. Opponents were sometimes united in their stance toward the government and coordinated their attacks, sometimes they followed their own particular agendas. In the preceding chapters, I derived important insights on the blame game style that characterizes each country.

Chapter 3 found that the UK political system makes it very difficult for opponents to reach their reputational and policy goals during a blame game. All the relevant institutional factors in the UK system are configured in favor of incumbents. Ministers constitute very strong blame shields for the government of the day, as they are usually only in office briefly and cannot be held personally accountable for a controversy due to very restrictive conventions of resignation. The administration bias injected by forms of agencification and reinforced by the work of parliamentary committees and their reports ensures that controversies often appear far away from the central government. The configuration of institutional factors in the UK system allows incumbents to ride out or to protract a controversy and leave the underlying policy problem(s) unaddressed. In the CSA, METRONET, DOME, and HCT cases, strong institutional blame protection created a relatively safe situation for incumbents. Overall, the UK blame game style is characterized by rather unaggressive and routinized interactions between the government and opponents.

Chapter 4 exposed a different blame game style in Germany. Institutional factors in the German political system are conducive to creating rather aggressive blame games in which political incumbents 
take center stage. The main reasons for this blame game style are extensive conventions of resignation and the opportunity to retrieve salient information about a controversy through the appointment of an inquiry commission. Both institutional factors are powerful tools that opponents can use to hold political incumbents accountable and to force them into heated blame game interactions. Unlike in the UK system where institutional factors comfortably protect political incumbents, incumbents in the German system often experience pressure to resign. Consequently, blamed incumbents must actively engage in blame management and may be forced to give in to opponents' policy demands. However, not all institutional factors are disadvantageous to political incumbents. In the NSU, BER, DRONE, and NITROFEN cases, incumbents benefited from an active and loyal governing majority and fragmentation among opponents. Whether the overall institutional configuration is more favorable to opponents or to incumbents largely depends on the degree of government involvement in a policy controversy. Overall, the German blame game style is characterized by aggressive and incumbent-centered interactions.

Chapter 5 showed that Switzerland features a blame game style that is very different from those of parliamentary systems. The Swiss political system features blame games that are characterized by interparty conflict that largely spares the politically responsible executive from participating in blame game interactions. This is very different from the more government opposition-centered blame games that occur in parliamentary systems. The main reason for this surprising pattern is that opponents cannot usually force incumbents to resign during a blame game. Opponents can only attempt to reach their policy goals. The CARLOS, TAX, EXPO, and MOB cases showed that in order to do so, opponents try to forge a pressure majority in parliament. A pressure majority consists of several parties that acknowledge the need for policy change in response to a controversy. Due to its collective and nonpartisan nature, the executive government is eager to express its cooperation with as many parties as possible and is thus unlikely to completely ignore the policy requests of the majority. A pressure majority, therefore, greatly increases the likelihood of the executive acting in the interest of opponents. Interparty conflict creates a comfortable situation for political incumbents. They are less likely to come under pressure, do not have to engage in intensive blame management, and can assume a rather neutral role during a blame game. Taken together, 
the Swiss political system exhibits a rather unaggressive, problemcentered blame game style.

In the following, I look at these similarities and differences systematically by comparing how the political interaction structure, institutionalized accountability structures, and institutional policy characteristics influence blame game interactions in the UK, German, and Swiss political systems. Overall, these comparisons suggest that institutional factors explain the basic form or setup of a blame game, determine gateways for blame attacks and barriers, and create a distinctive distribution of power between opponents and incumbents.

\subsection{Political Interaction Structure}

The institutionalized rules that structure interactions between political actors in democratic political systems during routine times also notably influence the basic structure of blame game interactions. Namely, they determine the coalitions that actors form and how those coalitions position themselves vis-à-vis each other. In each of the three political systems, one can observe a distinctive basic structure of blame game interactions. The UK political system exposes and pits the executive against the parliament. The German political system likewise exposes the executive but also provides it with strong support from the parliamentary majority. The Swiss cases revealed an altogether different basic structure in which some parties become opponents rather flexibly and primarily attack supporting parties to forge a pressure majority in parliament. As a result, political incumbents often fade into the background of blame game interactions. The political interaction structure determines who participates in a blame game, whether they participate as an opponent or a supporter, and whether political incumbents are forced to enter the fray or can remain at the sidelines.

\subsection{Institutionalized Accountability Structures}

The accountability structures enshrined in democratic political systems provide important gateways for blame attacks from opponents and blame barriers for incumbents by detailing the circumstances for which political incumbents can be held responsible. For opponents, these structures determine whom they can credibly blame for a controversy (political incumbents or administrative actors and entities) and whether they can 
blame the government as a whole or if they can single out individual politicians. In the UK and Swiss systems, accountability structures render it far more difficult for opponents to credibly blame the government or individual ministers/councilors than in the German system. This is why there are far more personalized attacks on political incumbents in the German system than in the UK and Swiss systems. Importantly, opponents also try to personalize a blame game when they are not after the resignation of incumbents but primarily want to change the trajectory of a policy. An incumbent under pressure is more likely to give in to policy demands. From the incumbents' perspective, accountability structures constitute more or less permeable blame barriers from their opponents' attacks. The more restrictive such accountability structures are, the less incumbents must do in terms of blame management when a controversy occurs. Incumbents that cannot be put under pressure are unattractive blame targets. Accountability structures in the UK and Swiss systems often allow incumbents to remain out of a blame game and avoid potentially threatening interactions with opponents. Accountability structures in the German system are less favorable to incumbents, as they often force them to engage in extensive blame management.

\subsection{Institutional Policy Characteristics}

The direct involvement of the government in a concrete policy issue is an important mediating factor that can tip the scales in favor of opponents or incumbents during a blame game. In modern and complex political systems, which often exhibit low direct government involvement, political incumbents are frequently far removed from policy controversies. This aggravates opponents' attempts to associate political incumbents with a controversy. Personalized blame attacks appear incredible in cases of low government involvement. Incumbents, on the other hand, possess more (credible) blame deflection possibilities when a controversy is far removed from them than when it is in a policy area where they are directly involved.

A comprehensive look at institutional factors and their combinations across political systems reveals the wide variety of ways that they produce incentives and constraints for the actors playing the blame game. Some institutional factors, such as the collegiality principle in Switzerland, or blurred ministerial responsibility in Germany, are idiosyncratic to a particular political system and thus yield particular 
effects on blame game interactions. Other institutional factors are similarly present across political systems but their causal relevance for the blame game differs across systems. The fragmentation in and between the sets of actors playing the blame game is more relevant in the Swiss than in the German system due to the importance for opponents to form a pressure majority in the Swiss system. Similarly, a parliamentary majority is more important during German blame games than during UK ones. In the latter system, incumbents do not need the support of the governing majority due to the ample blame protection offered by other institutional factors.

These observations highlight the interaction effects between institutional factors. Institutional factors combine to produce certain gateways for blame attacks and barriers against them. In the UK political system, restrictive conventions of resignation and generally low government involvement work together to create strong blame barriers for political incumbents. In the German system, blame barriers are more permeable because extensive conventions of resignation and the possibility of appointing an inquiry commission provide opportunities to put ministers under pressure. In Switzerland, strong fragmentation and the collegiality principle allow incumbents to keep out of blame game interactions. In addition to interaction effects, we also observe equifinality between different combinations of institutional factors. Equifinality means that different combinations of institutional factors lead to the same type of actions during a blame game (Schneider \& Wagemann, 2012). Namely, the cases reveal that incumbents sometimes manage to adopt a statesmanlike or 'above politics' position toward a controversy. In the three political systems, incumbents can adopt such a position for different reasons. In the Swiss system, this outcome occurs when there are distracted opponents who focus their blaming on the parties who support the executive. In the German system, a parliamentary majority acting as an attack device provides the incumbent with the reprieve needed to adopt an above politics position. Finally, in the UK system, strong blame protection from restrictive conventions of resignation and generally low government involvement facilitate the adoption of a statesmanlike position. Likewise, in both the UK and the Swiss political systems, opponents often spare political incumbents from blame. In the UK system, opponents are unable to do otherwise because restrictive conventions of resignation, frequent ministerial reshufflings, and generally low government involvement put ministers out of reach. In the Swiss system, institutional factors provide blame gateways for opponents but 
using them without securing a pressure majority in parliament would lead to nothing. Hence, there is functional equivalence of institutional factors as regards their effects on blame game interactions.

By looking at the influence of institutional factors as a whole, we see that they tend to produce unequal distributions of power between opponents and incumbents (Moe, 2005). In all three systems, opponents have a tough act to follow during blame games. This suggests that political systems are to some degree conflict-stable. They are not easily thrown off track by the political quarrels that they must digest at irregular intervals. Blame games, it seems, exhibit a status quo bias that is similar to that at work in democratic politics more generally (Hacker et al., 2015). Nevertheless, we see that the institutional terrain of a political system determines which goals opponents can reasonably pursue during a blame game. By emitting incentives and constraints, institutional factors decisively influence the type of payoff opponents can reasonably expect for generating blame. In the UK system, it is very difficult for opponents to pursue both reputational and policy goals. In the German system, opponents can pursue both reputational and policy goals. And in the Swiss system, policy goals are much more within reach than reputational goals.

While institutional factors determine important parameters of blame game interactions, they do not tell us how opponents and incumbents communicate with the public during a blame game. Institutional factors may tell us why opponents direct their attacks at the administrative level, but they do not tell us how exactly opponents blame administrative actors. Likewise, institutional factors inform us why incumbents can adopt a particular attitude toward a controversy, but this does not tell us what they expect from this attitude and what they intend to express to the public by adopting it. To account for these important aspects of blame game interactions, the next chapter lays a different analytical grid over the cases by examining the influence of issue characteristics on blame game interactions. 